This item was submitted to Loughborough's Research Repository by the author.

Items in Figshare are protected by copyright, with all rights reserved, unless otherwise indicated.

\title{
Influence of crank length and crank-axle height on standing arm-crank (grinding) power
}

PLEASE CITE THE PUBLISHED VERSION

http://dx.doi.org/10.1249/MSS.0b013e3181b2e8b4

PUBLISHER

Lippincott Williams \& Wilkins Inc. (@ American College of Sports Medicine (ACSM))

VERSION

AM (Accepted Manuscript)

LICENCE

CC BY-NC-ND 4.0

REPOSITORY RECORD

Neville, Vernon, Matthew T.G. Pain, Jonathan Kantor, and Jonathan P. Folland. 2019. "Influence of Crank Length and Crank-axle Height on Standing Arm-crank (grinding) Power". figshare.

https://hdl.handle.net/2134/6746. 
This item was submitted to Loughborough's Institutional Repository (https://dspace.lboro.ac.uk/) by the author and is made available under the following Creative Commons Licence conditions.

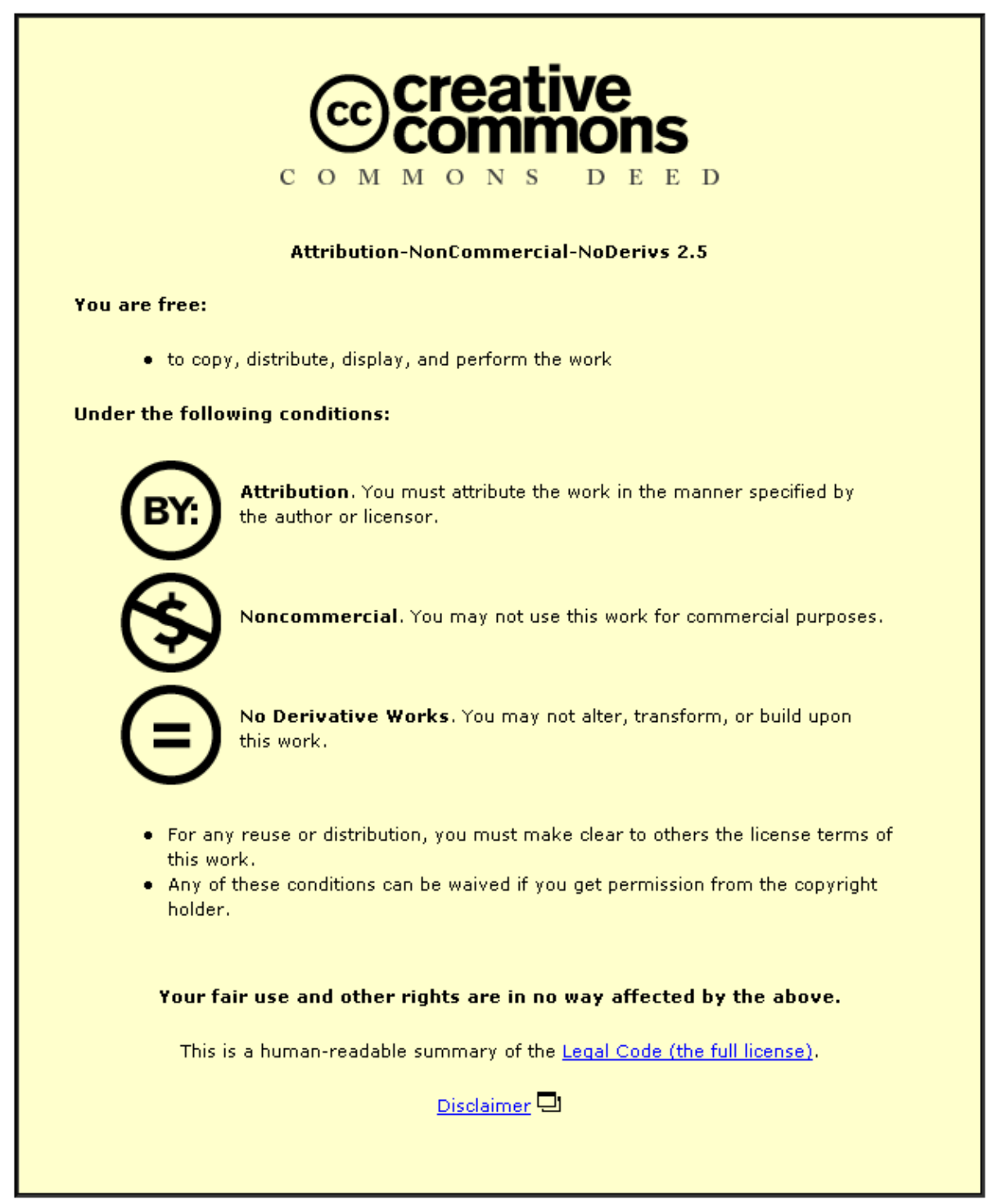

For the full text of this licence, please go to: http://creativecommons.org/licenses/by-nc-nd/2.5/ 


\title{
Influence of crank length and crank-axle height on standing arm-crank (grinding) power
}

\author{
Vernon Neville $^{1}$, Matthew T. G. Pain ${ }^{2}$, Jonathan Kantor ${ }^{2}$, and Jonathan P. Folland ${ }^{2}$ \\ ${ }^{1}$ Sports Technology Institute, Loughborough University, LE11 3TU, UK \\ ${ }^{2}$ School of Sport, Exercise \& Health Sciences, Loughborough University, LE11 3TU, UK
}

\begin{abstract}
Objective: To determine the optimal crank length and crank-axle height for maximum power production during standing arm-cranking ('grinding').

Methods: Nine elite professional America's Cup grinders (age: $36 \pm 2$ y; body mass: $104 \pm 1 \mathrm{~kg}$; body fat $13 \pm 2 \%$ ) performed eight maximal $6 \mathrm{~s}$ sprints on an adjustable standing arm-crank ergometer fitted with an SRM powercrank. The protocol included crank lengths of 162, 199, 236 and $273 \mathrm{~mm}$ and crank-axle heights of $850,950,1050$ and $1150 \mathrm{~mm}$. Peak power, ground reaction forces (GRF) and joint angles were determined and compared for different crank lengths and crank-axle heights with repeated-measures ANOVA.

Results: Peak power was significantly different between crank lengths $(\mathrm{P}=0.006)$, with $162 \mathrm{~mm}$ lower than all others $(\mathrm{P}<0.03)$. Optimal crank length was $12.3 \%$ of arm-span, or $241 \pm 9 \mathrm{~mm}$ for this cohort of athletes. Peak power was significantly less for the crank-axle height of $850 \mathrm{~mm}$ compared to $1150 \mathrm{~mm}(\mathrm{P}=0.01)$. The optimal crank-axle height for peak power was between 50 and $60 \%$ of stature $(950-1150 \mathrm{~mm}$ in this study). Hip flexion was greater at the lowest crank-axle height $(850 \mathrm{~mm})$ than at 1050 and $1150 \mathrm{~mm}(\mathrm{P}<0.01)$, and the resultant GRF was also reduced compared to all other heights, indicating greater weight bearing by the upper body.

Conclusions: Changes in crank length and crank-axle height influence performance during maximal standing arm-crank ergometry. These results, suggest that standard leg-cycle crank lengths are inappropriate for maximal arm-cranking performance. In addition, a crank-axle height of $<50 \%$ of stature, which is typically used in America's Cup sailing, may attenuate performance.
\end{abstract}

Keywords: Hand Cycle; Grinding; Upper body; America’s Cup; Sailing

\section{INTRODUCTION}

Arm-cranking, in particular standing arm-cranking has become increasingly popular as a means of assessing upper-limb performance $(2,6,17)$. However, the optimal configurations for power production during arm-cranking have not been determined. In cycling, the manipulation of joint angles, through changes in the structure of bicycle components, has been shown to influence performance $(5,10,21)$. For example, changes in seat height and cycle crank lengths directly affect hip and knee joint angles, the range of motion and angular velocity of the joints, and thus cycling performance (21). The optimal crank length for maximum power production has been reported to be $20 \%$ of leg length (10) and the optimal seat height appears to be $109 \%$ of inseam length (ischium to ground when standing) (5). It seems highly likely therefore that changes to the configuration of arm-crank ergometry, specifically crank length and crank-axle height, could also affect performance. Given the angle-torque and torque-velocity relationships of human muscle function, there is a clear rationale for how interventions that effect upper extremity joint range of motion and angular velocities may influence arm cranking performance.

Big-boat yacht racing is one of the only able bodied sports where arm-cranking is the primary physical activity. In the majority of professional big-boat yacht racing classes, manoeuvres are performed manually, without the assistance of stored energy, and armcranking ('grinding') is used to drive the winches, which in turn, controls the sails and mast (23). The average duration of grinding bouts during racing is $\sim 6 \mathrm{~s}$ with an exercise:rest ratio of 1:6 (13). International America's Cup Class version 5 yachts typically have four arm- 
crank stations ('grinding pedestals'), each manned by one or two athletes ('grinders'). The typical crank length and crank-axle height are 250 and $\sim 850 \mathrm{~mm}$, respectively, but there seems to be no scientific rationale for these settings. The height of the grinding crank-axle appears to have been largely determined by other aspects of yacht design, such as aerodynamics, related to boom and grinding pedestal heights, without an understanding or consideration of the effects of crank height on 'grinding' performance. Crank-axle height may influence posture, particularly hip flexion, as well as the relative weighting of the feet and the hands during grinding.

No studies have examined the effect of changes in crank length and crank-axle height on power production during standing arm-crank ergometry. The identification of optimal crank lengths and crank-axle heights would further our knowledge of standing arm-crank ergometry and may enhance the performance of America's Cup grinders. Therefore, the aim of this study was to assess the effects of different crank lengths and crank-axle heights on standing arm-cranking power and determine the optimal crank length and crank-axle height for maximum power production. Ground reaction forces beneath each foot and sagittal plane video were recorded to consider the biomechanical mechanisms for any changes in power with crank-axle height and crank length.

\section{METHODS}

\section{Participants}

Nine elite professional male America's Cup yacht racing grinders (mean $\pm \mathrm{SEM}$; age: $36 \pm 2$ y) volunteered to participate in this study. Their physical characteristics are shown in Table 1. The athletes had all represented teams that competed in the $32^{\text {nd }}$ America's Cup, with their collective experience including 28 America's Cup campaigns and 13 World Championship titles. Written informed consent was provided by all the athletes and the study was approved by the Loughborough University Ethical Advisory Committee.

\section{Anthropometry}

All anthropometric measurements were taken in accordance with the prescribed methods of the International Society for the Advancement of Kinanthropometry (9). Nude body mass was measured to the nearest $0.1 \mathrm{~kg}$ using a calibrated digital scale (Metler Toledo $\mathrm{KcC} 150$, Leicester, United Kingdom) and height was measured to the nearest $0.001 \mathrm{~m}$ using a stadiometer (Seca 222, Hamburg, Germany). Skinfold thickness was measured in duplicate at seven sites (triceps, biceps, subscapular, abdominal, supraspinale, thigh and medial calf) using calibrated skinfold callipers (Harpenden, Baty International, West Sussex, United Kingdom). Percentage body fat was calculated from the sum of seven skinfolds $(7,18)$. Arm span was measured with the athlete standing back against a wall, heels together and arms stretched out horizontally, and the distance between the tips of the furthest fingers on each hand was recorded (9). 
Table 1. Anthropometric characteristics of America's Cup “grinders"

\begin{tabular}{ccccccc}
\hline & $\begin{array}{c}\text { Body Mass } \\
{[\mathrm{kg}]}\end{array}$ & $\begin{array}{c}\Sigma 7 \text { Skinfolds } \\
{[\mathrm{mm}]}\end{array}$ & $\begin{array}{c}\text { Body Fat } \\
{[\%]}\end{array}$ & $\begin{array}{c}\text { Fat-free Mass } \\
{[\mathrm{kg}]}\end{array}$ & $\begin{array}{c}\text { Height } \\
{[\mathrm{m}]}\end{array}$ & $\begin{array}{c}\text { Arm span } \\
{[\mathrm{m}]}\end{array}$ \\
\hline Mean & $103.6 \pm 1.3$ & $71 \pm 8$ & $13 \pm 2$ & $89.8 \pm 1.8$ & $1.90 \pm 0.01$ & $1.96 \pm 0.02$ \\
Range & 100.3 to 109.9 & 35 to 106 & 6 to 24 & 76.7 to 94.7 & 1.83 to 1.95 & 1.86 to 2.05 \\
\hline
\end{tabular}

Data are presented as mean $\pm \operatorname{SEM}(n=9)$

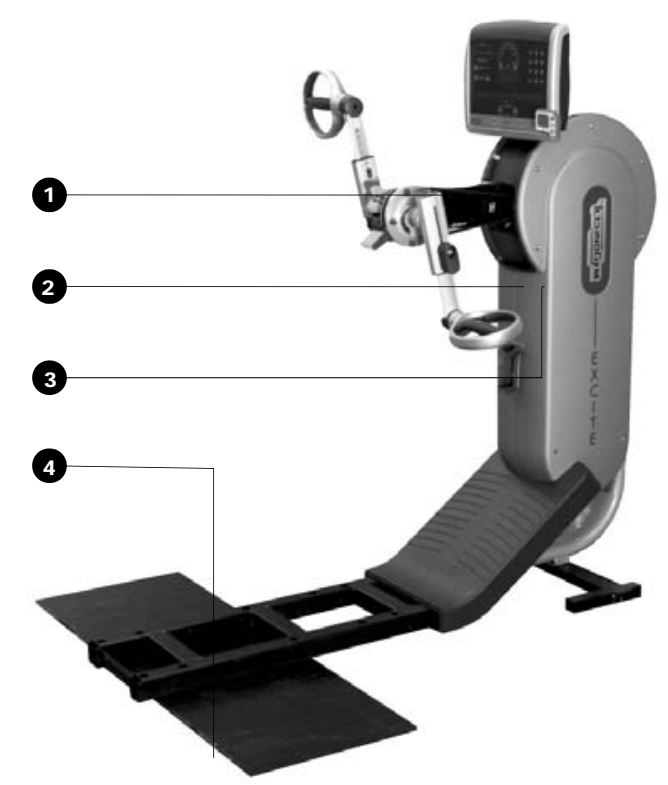

Figure 1. Adjustable standing arm-crank ergometer (Technogym Top Excite). (1) Adjustable crank length, (2) SRM scientific powercrank, (3) Adjustable crank-axle height, (4) Ground reaction force platforms (Kistler).

\section{Experimental design}

All tests were conducted between $09 \mathrm{~h} 00$ and 12h00. Anthropometric measurements were taken on arrival at the laboratory. After an initial 10 min self-paced warm-up, athletes performed eight maximum effort sprints at pre-determined combinations of crank length and crank-axle height in a randomised order. Due to the limited time available to test the athletes, not all possible combinations of crank length and crank-axle height were explored. The protocol included four variable crank lengths selected throughout the range available on the ergometer (162, 199, 236 and $273 \mathrm{~mm}$ ) and encompassing $170 \mathrm{~mm}$ (standard cycle cranks) and $250 \mathrm{~mm}$ (grinding pedestal cranks) at a constant crank-axle height of $1050 \mathrm{~mm}$ (determined as the optima during a previous pilot study), and four variable crank-axle heights $(850,950,1050$ and $1150 \mathrm{~mm}$ ) with a constant crank length of $250 \mathrm{~mm}$ (the standard length on America's Cup yachts). Each sprint was $6 \mathrm{~s}$ in duration with a 10 min rest interval between sprints to ensure complete recovery. A $5 \mathrm{~s}$ countdown was given prior to the start of each sprint during which time a crank velocity of $\sim 50 \mathrm{rpm}$ was maintained. Verbal encouragement was given throughout the test. Torque and angular velocity (crank velocity) were recorded throughout each sprint and analysed off-line. Power was determined as the product of torque $(T)$ in Newton metres and crank velocity $(\omega)$ expressed in radians $\mathrm{s}^{-1}$. 


\section{Arm-crank Ergometer}

All tests were conducted on an adjustable standing arm-crank ergometer (Technogym Top Excite, Gambettolla, Italy), which was secured to the ground whilst remaining clear of the force plates (Figure 1). The athletes were all familiar with the ergometer used in this study which is commonly used in America's Cup training. The resistance software of the ergometer was upgrade (Technogym Excite version SW50.22.7) to provide increased resistance, and set at level 30 ( $\sim 92 \mathrm{~N}$ according to the manufacturers specifications). The crank handles were $0.52 \mathrm{~m}$ apart (medio-lateral displacement) which was slightly wider than standard grinding pedestals $(0.48 \mathrm{~m})$. An SRM power crank (Schoberer Rad Messtechnik, Science Powermeter V, Jülich, Germany) was fitted to the centre axle of the ergometer. Torque was recorded continuously at $200 \mathrm{~Hz}$ (SRM torque software) and averaged over $360^{\circ}$. Crank velocity was measured every revolution (SRM torque software). The SRM Powercrank was calibrated prior to each test protocol, according to the manufacturer's guidelines.

Table 2. Peak Power during maximal arm cranking of varying crank lengths and crank-axle heights

\begin{tabular}{|c|c|c|c|c|c|c|c|c|}
\hline & \multicolumn{4}{|c|}{ Crank Length [mm] } & \multicolumn{4}{|c|}{ Crank-axle Height [mm] } \\
\hline & 162 & 199 & 236 & 273 & 850 & 950 & 1050 & 1150 \\
\hline Peak Power & $1153 \pm 56^{a}$ & $1276 \pm 47$ & $1335 \pm 66$ & $1303 \pm 46$ & $1252 \pm 43^{b}$ & $1340 \pm 51$ & $1303 \pm 53$ & $1347 \pm 46$ \\
\hline Range & 929 to 1379 & 1078 to 1455 & 1104 to 1691 & 1127 to 1523 & 1062 to 1442 & 1187 to 1609 & 1138 to 1649 & 1151 to 1523 \\
\hline
\end{tabular}

${ }^{a}$ less than all crank lengths $(P<0.03) ;{ }^{b}$ less than crank-axle height $1150(P=0.05) ;$ Data mean $\pm S E M(n=9)$

\section{Vertical ground reaction force}

In order to assess differences in unilateral weight shifting due to the independent variables Ground Reaction Forces (GRF) beneath each foot were measured using two calibrated force platforms (Kistler Instrument AG, 9253A2 [right] and 9281CA [left], Winterthur, Switzerland) with a sampling rate of $200 \mathrm{~Hz}$ and 16 bit ADC. The arm-crank ergometer was positioned centrally over the two force platforms to allow the athletes to stand with one foot on each platform. The force platforms were calibrated according to the manufacturer's guidelines and zeroed prior to each sprint. The ground reaction forces were analysed for each sprint over $5 \mathrm{~s}$, beginning $1 \mathrm{~s}$ after the start of the sprint. For each force plate the magnitude of the resultant GRF and its direction in the $X-Z$ plane (towards the ergometer) were calculated from the $\mathrm{X}, \mathrm{Y}$ and $\mathrm{Z}$ components. For both plates the $\mathrm{Z}$ axis was vertical, the $\mathrm{Y}$ axis pointed perpendicular to a line joining the ergometer to the centre of the two force plates and the $\mathrm{X}$ axis was perpendicular to $\mathrm{Z}$ and $\mathrm{Y}$. The variation in torque amplitude and direction was calculated as the standard deviation of the resultant GRF and its direction. 


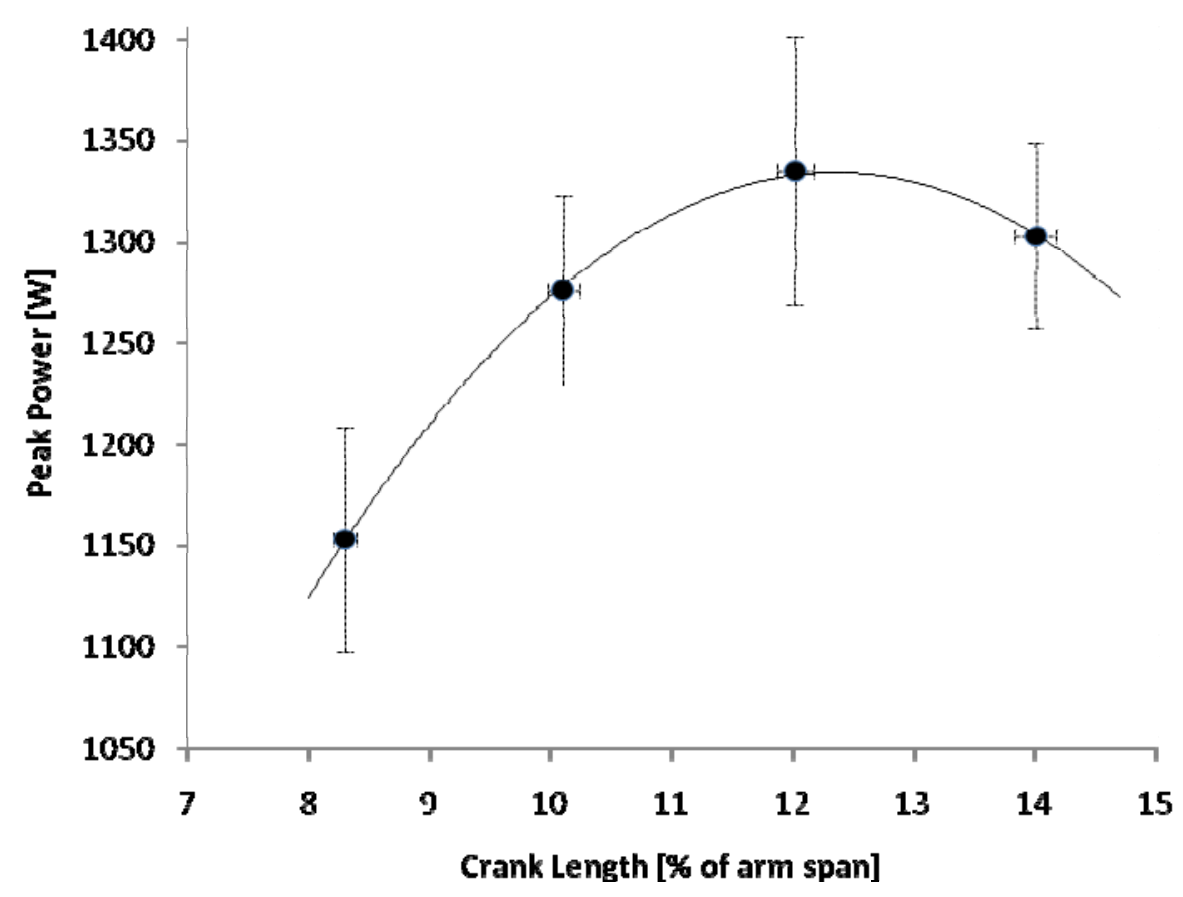

Figure 2. Relationship between Peak Power and Crank Length (CL), as a percentage of arm span, during standing arm cranking ('grinding'). The regression equation was: Power $=-11.127(\mathrm{CL})^{2}+$ 274.7(CL) - $361.2(\mathrm{r}=1.0, \mathrm{n}=9)$. Data are mean \pm SEM. * Significantly less than all other crank lengths $(\mathrm{P}<0.03)$

\section{Video analysis}

Reflective markers were attached to the right side of each athlete at the following anatomical positions: iliac crest, greater trochanter and lateral epicondyle of the femur, and lateral malleolus of the fibula. All sprints were recorded by a video camera (Panasonic NVDS99EG mini DV, Japan) at $25 \mathrm{~Hz}$, which was positioned perpendicular to the sagital plane of the ergometer, $7 \mathrm{~m}$ from the athletes and at a fixed height of $1 \mathrm{~m}$. Four $500 \mathrm{~W}$ lamps were projected onto the athlete to provide additional lighting. Hip joint angle, between the iliac crest, greater trochanter and the knee, knee joint angle and foot-to-floor angle were measured after $3 \mathrm{~s}$ of maximal grinding, on the right side of the body, when the right knee was at maximum extension. The determination of joint angles was performed using a digital software program (SiliconCOACH PRO, Dunedin, New Zealand). 


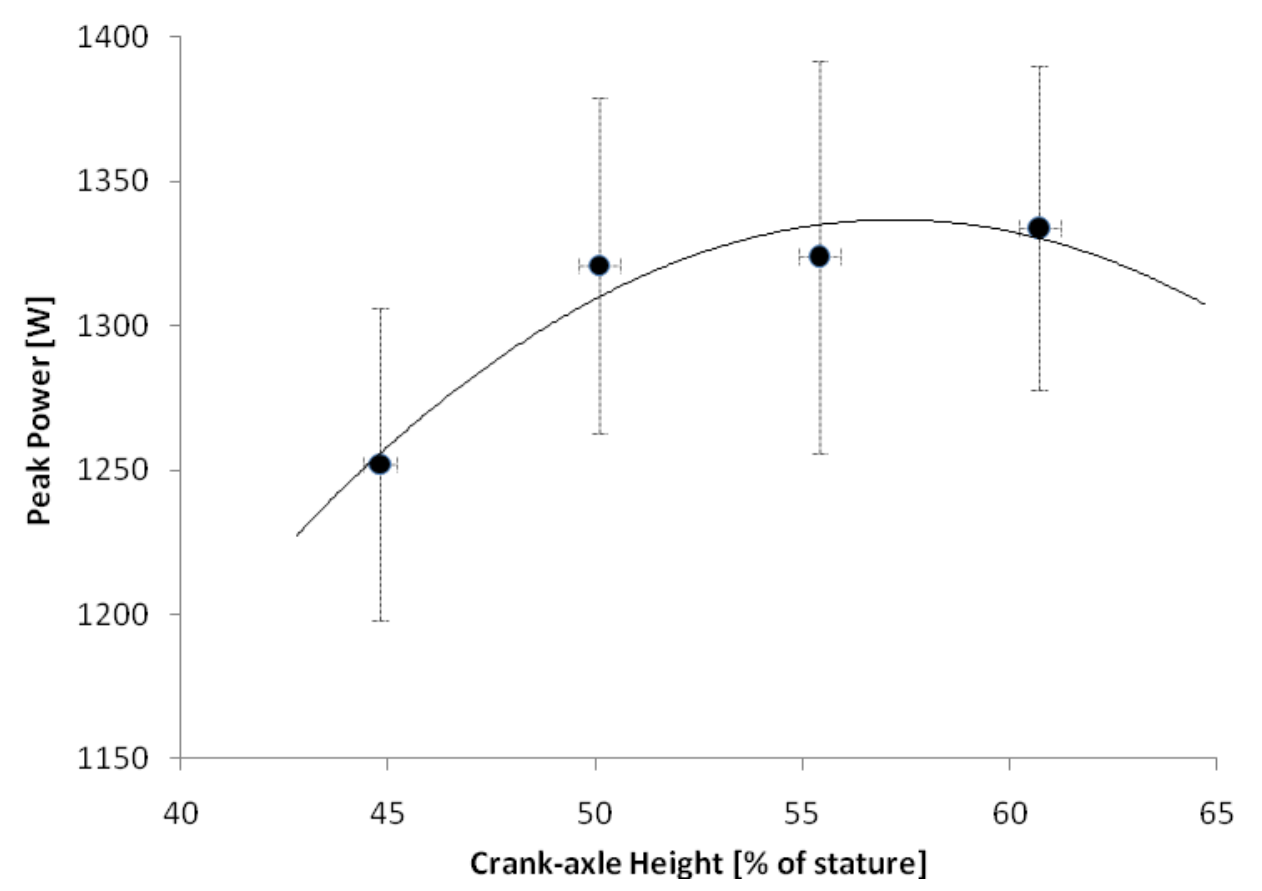

Figure 3. Relationship between Peak Power and Crank-axle Height, as a percentage of stature, during standing arm cranking ('grinding'). Data are mean $\pm \operatorname{SEM}(\mathrm{r}=0.97, \mathrm{n}=7)$. * Significantly less than Crank-axle Height of $60.7 \%$ of stature $(\mathrm{P}=0.01)$
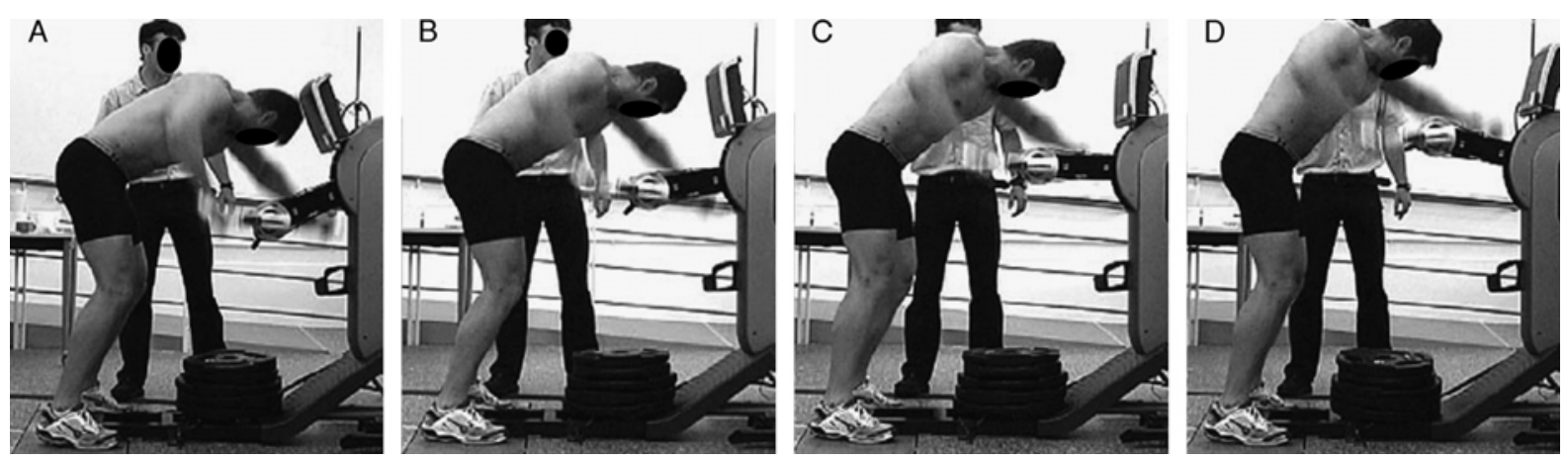

Figure 4. Images showing grinding at different crank-axle heights $(A=850 \mathrm{~mm}, \mathrm{~B}=950 \mathrm{~mm}, \mathrm{C}=1050 \mathrm{~mm}, \mathrm{D}$ $=1150 \mathrm{~mm})$. For the group, the hip angle in panel A was significantly less than those in panels $\mathrm{C}$ and $\mathrm{D}(\mathrm{n}=7, \mathrm{P}<0.01)$.

\section{Statistical analysis}

Peak power, joint angles, resultant GRF and GRF direction for the different crank lengths and crank-axle heights were compared with one-way repeated-measures ANOVA for each independent variable. Bonferroni post-hoc tests were used to determine where any differences lay. Pearson product-moment correlation coefficients were calculated to assess bivariate relationships. Analyses were performed using SPSS for Windows version 15.0. The group data describing the relationships between crank-axle height and crank length with peak power were fitted with quadratic (parabolic) relationships using SPSS, which generated theoretical optimum values for each parameter. Significance was defined as $\mathrm{P} \leq 0.05$, and all data are presented as mean $\pm \mathrm{SEM}$. 


\section{RESULTS}

The athletes were characterised as having a high fat-free mass (Table 1). There was a significant difference in peak power between crank lengths $(\mathrm{P}=0.006)$, with a lower peak power for $162 \mathrm{~mm}$ than all other crank lengths $(\mathrm{P}<0.03$, Table 2$)$. When crank length was normalised for arm-span, the relationship between maximum power and crank length (CL) was parabolic and fitted by the equation: Power $=-11.127(\mathrm{CL})^{2}+274.7(\mathrm{CL})-361.2 ; \mathrm{r}=1.0$ (Figure 2). From this relationship, the highest theoretical peak power occurred at a crank length of $12.3 \%$ of arm span which in these grinders equated to $241 \pm 9 \mathrm{~mm}$.

Peak power was significantly less for the crank-axle height of $850 \mathrm{~mm}$ compared to $1150 \mathrm{~mm}(\mathrm{P}=0.01)$ (Table 2). Prior to normalising crank-axle height to stature, two athletes were excluded from the data analysis as they exhibited significant differences in technique from all other athletes. This included substantial ankle plantar flexion, measured by foot-floor angle $\left(53 \pm 4^{\circ}\right.$ and $42 \pm 5^{\circ}$ for the excluded athletes vs. $4 \pm 2^{\circ}$ for the remaining athletes, ANOVA $\mathrm{P}<0.001$ ), thereby confounding their true stature. The maximum power and crankaxle height relationship revealed similar high values between 50 and $60 \%$ of stature (Figure 3 ), which was $950-1150 \mathrm{~mm}$ in this cohort of grinders. When the data between maximum power and crank-axle height $(\mathrm{CAH})$ was modelled with a parabolical relationship (Power = $\left.0.5251(\mathrm{CAH})^{2}+60.096(\mathrm{CAH})-382.76 ; \mathrm{r}=0.97\right)$ the theoretical optimum for crank-axle height for the group $(\mathrm{n}=7)$ was $57.3 \%$ of stature. Hip joint angle during arm-cranking was influenced by crank-axle height ( $\mathrm{P}=0.001$, Figure 4$)$, with significantly greater hip flexion at $850 \mathrm{~mm}$ than at 1050 and $1150 \mathrm{~mm}\left(127 \pm 3^{\circ}\right.$ vs. $142 \pm 3^{\circ}$ and $146 \pm 3^{\circ}$ respectively, $\mathrm{P}<0.01$, $\mathrm{n}=7)$, but similar to $950 \mathrm{~mm}\left(136 \pm 3^{\circ}\right)$. Knee joint angle was unaffected by crank-axle height

Table3. GRF resultant (body weight) and direction (degrees) during maximal standing arm-cranking sprints with varying crank lengths and crank-axle heights

Crank Length (mm)

Crank-Axle Height (mm)

\begin{tabular}{|c|c|c|c|c|c|c|c|c|c|}
\hline & & 162 & 199 & 236 & 273 & 850 & 950 & 1050 & 1150 \\
\hline $\begin{array}{l}\text { GRF } \\
\text { resultant } \\
\text { (bw†) }\end{array}$ & $\mathrm{D}$ & $0.51 \pm 0.014^{*}$ & $0.51 \pm 0.011$ & $0.52 \pm 0.014^{*}$ & $0.52 \pm 0.011^{*}$ & $0.47 \pm 0.010^{*}$ & $0.50 \pm 0.012$ & $0.51 \pm 0.013$ & $0.52 \pm 0.011$ \\
\hline $\begin{array}{l}\text { GRF } \\
\text { resultant } \\
\text { (bw†) }\end{array}$ & ND & $0.47 \pm 0.013$ & $0.47 \pm 0.016$ & $0.46 \pm 0.016$ & $0.46 \pm 0.018$ & $0.43 \pm 0.014$ & $0.45 \pm 0.014$ & $0.47 \pm 0.015$ & $0.48 \pm 0.014$ \\
\hline $\begin{array}{l}\text { GRF } \\
\text { resultant } \\
\text { (bw†) }\end{array}$ & Mean & $0.49 \pm 0.011$ & $0.49 \pm 0.010$ & $0.49 \pm 0.011$ & $0.49 \pm 0.009$ & $0.45 \pm 0.010 \dagger$ & $0.47 \pm 0.008 \ddagger$ & $0.49 \pm 0.010 \S$ & $0.50 \pm 0.007 \mathrm{k}$ \\
\hline $\begin{array}{l}\text { GRF } \\
\text { direction } \\
(-)\end{array}$ & $\mathrm{D}$ & $90.4 \pm 2.58$ & $92.0 \pm 2.71$ & $916 \pm 2.80$ & $9270 \pm 2.71$ & $92.5 \pm 2.77$ & $87.2 \pm 2.63$ & $87.9 \pm 2.85$ & $90.2 \pm 2.54$ \\
\hline $\begin{array}{l}\text { GRF } \\
\text { direction } \\
(-)\end{array}$ & ND & $92.1 \pm 1.10$ & $89.8 \pm 1.78$ & $88.5 \pm 1.46$ & $91.6 \pm 1.57$ & $93.4 \pm 1.54$ & $91.1 \pm 1.71$ & $89.3 \pm 1.78$ & $87.7 \pm 1.10$ \\
\hline $\begin{array}{l}\begin{array}{l}\text { GRF } \\
\text { direction } \\
(-)\end{array} \\
\end{array}$ & Mean & $91.2 \pm 1.33$ & $90.9 \pm 1.76$ & $90.0 \pm 1.65$ & $92.2 \pm 1.73$ & $93.0 \pm 1.85$ & $89.2 \pm 1.78$ & $88.6 \pm 2.03$ & $89.0 \pm 1.42$ \\
\hline
\end{tabular}

Data are presented as mean \pm SEM $(n=9)$; America's Cup IACC version 5 yachts have a standard crank length and a crankaxle height of 250 and $850 \mathrm{~mm}$, respectively.

* Dominant leg (D) greater than the nondominant leg (ND), P G 0.05 .

$\dagger$ Less than all others, P G 0.01 .

¥ Less than 1050 and $1150 \mathrm{~mm}, \mathrm{P} \mathrm{G} 0.01$.

\& Greater than 850 and $950 \mathrm{~mm}, \mathrm{P} \mathrm{G} 0.01$.

k Greater than 850 and 950 mm, P G 0.002 . 
Table 4. SD of GRF resultant (body weight) and direction (degrees) during maximal standing arm-cranking sprints with varying crank lengths and crank-axle heights

Crank Length (mm) Crank-Axle Height (mm)

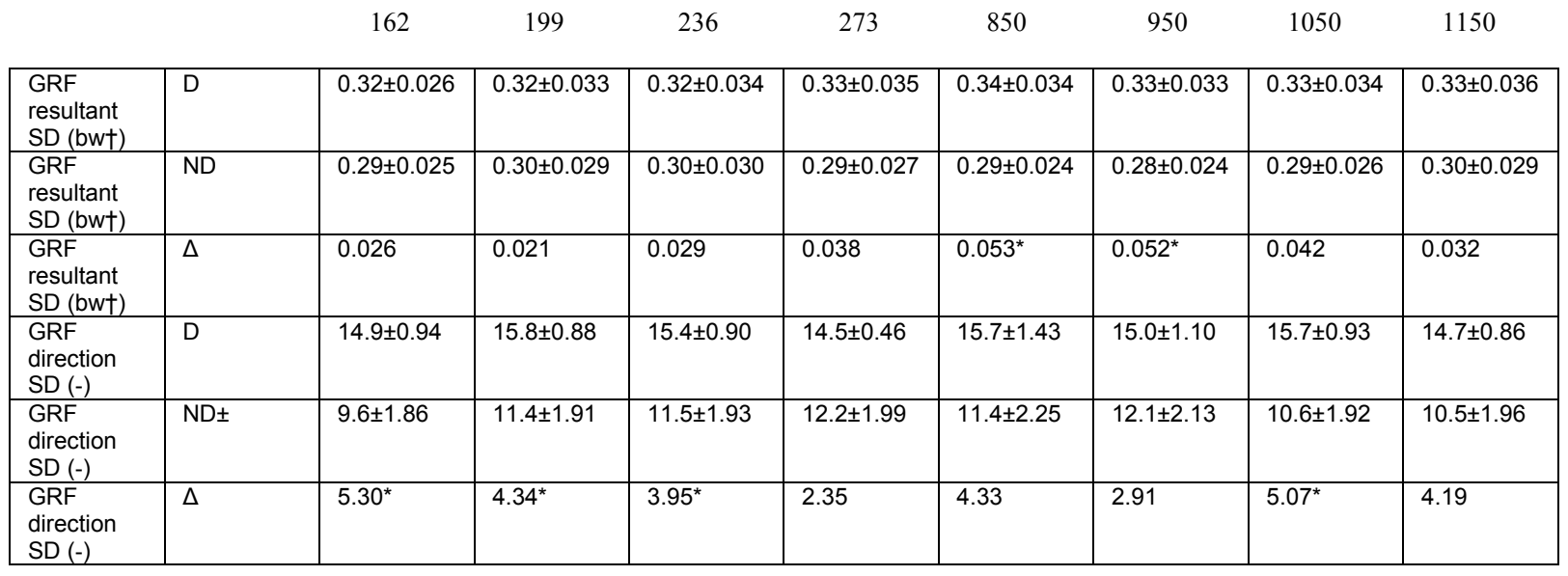

Data are presented as mean \pm SEM $(n=9)$; America's Cup IACC version 5 yachts have a standard crank length and a crank-axle height of 250 and $850 \mathrm{~mm}$, respectively.

* Dominant leg (D) greater than the nondominant leg (ND), P G 0.05 .

The mean resultant GRF was significantly different between crank-axle heights $(\mathrm{P}<0.001$, Table 3), with $850 \mathrm{~mm}$ less than all other heights $(\mathrm{P}<0.01)$ and $950 \mathrm{~mm}$ less than 1050 and $1150 \mathrm{~mm}$, respectively $(\mathrm{P}<0.01)$, whereas the mean resultant GRF was not influenced by crank length. The mean GRF direction was unaffected by crank length or crank-axle height. When comparing differences between legs, resultant GRF was greater for the dominant leg than the non-dominant leg for crank lengths, 162, 236 and $273 \mathrm{~mm}$, and crank-axle height $850 \mathrm{~mm}$. When comparing the variability in amplitude and direction between legs (Table 4), the dominant leg had significantly greater amplitude at crank-axle heights of $850 \mathrm{~mm}$ and $950 \mathrm{~mm}$ and greater variability in direction at crank lengths of 162, 199 and $236 \mathrm{~mm}$, respectively.

\section{DISCUSSION}

The main findings of this study were that changes in crank length and crank-axle height influenced performance during maximal standing arm-crank ergometry. The parabolic curves observed for peak power with increasing crank lengths and crank-axle heights can be attributed to interactions between torque, crank velocity, and posture. The design and configuration of arm-crank ergometers and grinding pedestals should recognise the importance of these variables to performance, and we suggest an optimum crank length of 12 - $12.5 \%$ of arm span and an optimum crank-axle height of $50-60 \%$ of stature ( 241 and $\sim 1087 \mathrm{~mm}$, respectively, in this cohort of grinders).

The peak power values reported in this study (range: 1203 - $1691 \mathrm{~W}$, Table 2) are among the highest reported during arm-cranking. Similar impressive peak power values have been reported previously in America's Cup grinders (15). To our knowledge America's Cup grinders are the only athletes to have reported arm-crank peak power values greater than 1000 $\mathrm{W}$. This is likely due to the unique nature of this cohort of athletes, who are selected and trained for the specific activity of standing arm-cranking $(12,15)$, and the use of more favourable arm-crank configurations than have often been employed. When the data were normalised for the substantial stature of the athletes, the relative peak power $\left(13.8 \mathrm{~W} \mathrm{~kg}^{-1}\right.$; range: $11.5-16.9 \mathrm{~W} \mathrm{~kg}^{-1}$ ) were still greater than other trained upper body athletes 
(swimmers, $11.5 \mathrm{~W}^{-1} \mathrm{~kg}^{-1}(11)$; elite gymnasts, $10.6 \mathrm{~W} \mathrm{~kg}^{-1}$ (8); elite wrestlers, $9.6 \mathrm{~W} \cdot \mathrm{kg}^{-1}(6)$; javelin throwers, $\left.8.5 \mathrm{Wkg}^{-1}(2)\right)$. The reliability of peak power data during seated armcranking in untrained individuals has been determined to have a CV of $<5 \%$ (19), and the athletes in this study were all highly trained and familiar with the ergometer used.

The selection of optimal arm-crank length for maximal power may be of interest to bigboat grinders and to studies using standing arm-crank ergometry as a measure of performance. Our data demonstrate that the optimal crank length for maximal power production was $\sim 12.3 \%$ of arm span, which equated to an optimal average crank length of $\sim 241 \mathrm{~mm}$ (range, 228 to $252 \mathrm{~mm}$ ) in this cohort of athletes (Figure 2). This optimum crank length for the cohort was within $4 \%(9 \mathrm{~mm})$ of the standard crank length used on America's Cup racing yachts ( $250 \mathrm{~mm}$ or $12.8 \%$ of arm span in this cohort). From the crank lengthpower relationship (Figure 2), this equates to a reduction in power of $<0.2 \%$ for the standard grinding pedestal crank length compared to the optimum we have found. Essentially, the standard crank length used in big-boat sailing facilitates very close to optimal power production for these elite grinders who have a wide arm span. Overall, the $68 \%$ variation in crank lengths used in this study elicited a $16 \%$ variation in maximum arm-cranking power, which is considerably greater than the variation reported in cycling (10). The optimal crank length in cycling has been determined to be $20 \%$ of leg length which equates to $\sim 170 \mathrm{~mm}$ for the average population (10). Standard leg cycling cranks (170 to $180 \mathrm{~mm}$ ) have also been used extensively for arm-crank ergometry studies, with the pedals replaced by handles $(2,19$, $20,22)$. This length of crank appears to be substantially less than the optimum we have found in this cohort, and based on our data would have resulted in a $13 \%$ reduction in power production, although individual differences in physique might attenuate the magnitude of this decrement. It is important to note that these findings relate specifically to standing armcranking and may differ when seated.

The influence of crank length on performance is due to the complex interaction of force, torque and velocity (4). Shorter crank lengths tend to decrease torque and elevate crank velocity (10). Therefore grinding at different crank lengths involves changing the contractile conditions across the range of the power-velocity relationship. As the power-crank velocity relationship is parabolic $(3,10)$, it is not surprising therefore that the power-crank length relationship is also parabolic. Hence peak performance (power) occurs at an optimum combination of torque and velocity.

In order to remove differences in anthropometry and provide a normalised measurement, crank-axle height was calculated relative to stature. However, two athletes had an obviously different technique to the rest of the cohort, which included substantial plantar flexion of the ankle that changed their effective stature, and they were therefore excluded from the relative height data.

Contrary to that found in cycling (5), the parabolic curve for crank-axle height was a poor fit with no clear optimum but resembled more of a plateau. There was little difference in performance between crank-axle heights of 50 to $60 \%$ of stature, however, peak power was significantly reduced when the crank-axle height was less than $50 \%$ of stature. These results indicate that the typical height of the grinding pedestals used on America's Cup yachts $(\sim 850$ $\mathrm{mm}$ ) would reduce peak power by as much as $7 \%$ for the athletes tested in this study. Unfortunately, the highest crank-axle height investigated in this study was $60.7 \%$ of stature, as it would have been interesting to determine the effect of greater heights. It should be noted that it is possible that an interaction exists between crank-axle height and crank arm length and that some other combination of crank-axle height and crank arm length may have produced even higher (optimal) peak power outputs than observed in this study. 
In cycling, seat-to-pedal height distance influences performance due to changes in joint angle at the hip and knee (5). Although it could be assumed that crank-axle height may have a similar effect on standing arm-crank performance, the joints with the greatest range of motion during arm-cranking, the elbow and shoulder, are probably not directly affected by the crankaxle height. Rather, it is the hip angle which had the greatest change according to the crankaxle height. The increased hip flexion at lower crank-axle heights resulted in an increased portion of the athlete's body mass being supported by the ergometer, as shown by the decreased resultant GRF through the feet, presumably due to the athletes centre of gravity shifting forwards. The additional weight bearing of the upper limbs in this off-balance position results in an increase in energy required to move the limbs and to stabilise the upper body. This internal work is likely to be greater when the athlete is in an unbalanced posture, reducing the energy available at the crank, and may explain the attenuated peak power at the lowest crank-axle height. Another consideration is that with the increased hip flexion at lower crank-axle heights (Figure 4), the load on the lower back would be expected to be greater. The incidence of lumbar spine injuries in America's Cup yacht racing is high $(1,14,16)$, and this has been previously attributed to the forward flexed and rotated position of the spine during grinding at the standard grinding pedestal height $(1,16)$. The use of EMG and 3D kinematic analysis is recommended to investigate optimal body posture and joint angles on the technique of grinding performance, specifically changes in upper limb joint angles and the relationship between upper and lower limbs.

When comparing the ground reaction force between legs, the greater resultant force magnitude of the dominant leg suggests a degree of asymmetry in the forces being produced by the non-/dominant sides (Table 3). This finding echos observations by Smith et al., (2008) who used non-specifically trained participants during seated, sub-maximal arm-crank ergometry. Using torque data, these authors demonstrated that the propulsive forces produced by the dominant arm were greater than those of the contra-lateral limb, and suggested this might place an over reliance on the dominant arm to produce effective forces. Taken together these findings clearly indicate there to be a bilateral asymmetry in the forces generated during arm-cranking. In addition, the variation in the resultant GRF was greater for the dominant leg at lower crank-axle heights, indicating greater amplitude of the GRF during each crank revolution in this leg at these positions, whereas there was little difference between legs with varying crank lengths (Table 4). However, the dominant leg had greater variability in direction as the crank length shortened. Taken together this seems to indicate that in the less mechanically efficient arm-crank configurations, the contribution of the dominant side increases. Further investigation is clearly warranted in order to identify the aetiology of asymmetry in force generation during arm-cranking.

\section{Conclusions}

Crank length and crank-axle height influence performance in standing arm-crank ergometry. The optimal crank length for maximal power was $12-12.5 \%$ of arm-span or 235 $245 \mathrm{~mm}$ for the cohort in this study. These results, suggest that standard leg cycle crank lengths are inappropriate for maximal standing arm-cranking performance in elite America's Cup grinders. Optimal crank-axle height was between 50 and $60 \%$ of stature $(950-1150 \mathrm{~mm}$ in this study), and a crank-axle height of $<50 \%$ of stature, which is typically used in America's Cup sailing, may result in reduced performance. The design and configuration of arm-crank ergometers and grinding pedestals should use these findings in optimising performance. Future research should investigate the contribution of the lower limbs to standing arm-crank performance. 


\section{Acknowledgements:}

We are grateful to the athletes who travelled from various parts of the World to participate in this study. Our gratitude is also extended to the SPORTS TECHNOLOGY INSTITUTE (www.sports-technology.com) for providing the laboratory facilities and to TECHNOGYM ${ }^{\mathrm{TM}}$ (Gambettola, Itally) for supplying the arm-crank ergometer used in this study.

The results of the present study do not constitute endorsement by ACSM.

\section{Conflict of interest:}

The authors are not aware of any conflict of interest. The arm-crank ergometer used in this study was provided by Technogym ${ }^{\mathrm{TM}}$.

\section{Ethical Standards:}

To the best of our knowledge the experiments comply with current laws.

\section{REFERENCES:}

Allen JB. Sports Medicine Injuries in the America's Cup 2000. New Zealand journal of sports medicine. 2005; 33 (2): 43-47.

Bouhlel E, Chelly MS, Tabka Z, Shephard R. Relationships between maximal anaerobic power of the arms and legs and javelin performance. J Sports Med Phys Fitness. 2007; 47 (2): 141-6.

Dorel S, Hautier CA, Rambaud O et al. Torque and power-velocity relationships in cycling: relevance to track sprint performance in world-class cyclists. Int J Sports Med. 2005; 26 (9): 739-46.

Gardner AS, Martin JC, Martin DT, Barras M, Jenkins DG. Maximal torque- and powerpedaling rate relationships for elite sprint cyclists in laboratory and field tests. Eur J Appl Physiol. 2007; 101 (3): 287-92.

Hamley EJ, Thomas V. Physiological and postural factors in the calibration of the bicycle ergometer. J Physiol. 1967; 191 (2): 55P-56P.

Hubner-Wozniak E, Kosmol A, Lutoslawska G, Bem EZ. Anaerobic performance of arms and legs in male and female free style wrestlers. J Sci Med Sport. 2004; 7 (4): 473-80.

Jackson AS, Pollock ML. Generalized equations for predicting body density of men. $\mathrm{Br} J$ Nutr. 1978; 40 (3): 497-504.

Jemni M, Sands WA, Friemel F, Stone MH, Cooke CB. Any effect of gymnastics training on upper-body and lower-body aerobic and power components in national and international male gymnasts? J Strength Cond Res. 2006; 20 (4): 899-907.

Marfell-Jones M, Olds T, Stewart A, Carter L. International Standards for Anthropometric Assessment. ISAK: Potchefstroom, South Africa, 2006; 32-89.

Martin JC, Spirduso WW. Determinants of maximal cycling power: crank length, pedaling rate and pedal speed. Eur J Appl Physiol. 2001; 84 (5): 413-8.

Mercier B, Granier P, Mercier J, Trouquet J, Prefaut C. Anaerobic and aerobic components during arm-crank exercise in sprint and middle-distance swimmers. Eur J Appl Physiol Occup Physiol. 1993; 66 (5): 461-6.

Neville V. America's Cup yacht racing is not just about the boat. Sport Exerc Sci. 2008; March (15): 26-27.

Neville V. The physiological demands of America's Cup yacht racing. Loughborough University, School of Sports and Exercise Sciences, Loughborough, 2008; Doctoral Thesis: 67-71. 
Neville V, Folland JP. The epidemiology and aetiology of injuries in sailing. Sports Med. 2009; 39 (2): 129-145.

Neville V, Pain MT, Folland JP. Aerobic power and peak power of elite America's Cup sailors. Eur J Appl Physiol. 2009; 106: 149-157.

Neville VJ, Molloy J, Brooks JH, Speedy DB, Atkinson G. Epidemiology of injuries and illnesses in America's Cup yacht racing. Br J Sports Med. 2006; 40 (4): 304-11; discussion 311-2.

Pearson S, Hume P, Slyfield D, Cronin J. External work and peak power are reliable measures of ergometer grinding performance when tested under load, deck heel, and grinding direction conditions. Sports Biomech. 2007; 6 (1): 71-80.

Siri WE. Body composition from fluid space and density. In: Techniques for measuring body composition. Brozek J, Hanschel A (Eds.) Washington, DC: National Academy of Science, 1961, pp. 223-244.

Smith PM, Price MJ, Davison RC, Scott D, Balmer J. Reproducibility of power production during sprint arm ergometry. J Strength Cond Res. 2007; 21 (4): 1315-9.

Smith PM, Chapman ML, Hazlehurst KE, Goss-Sampson MA. The influence of crank pattern on muscle activity and torque production during arm crank ergometry. $J$ Electromyogr Kinesiol. 2008; 18: 598-605.

Too D, Landwer GE. The effect of pedal crank arm length on joint angle and power production in upright cycle ergometry. J Sports Sci. 2000; 18 (3): 153-61.

Vandewalle H, Peres G, Sourabie B, Stouvenel O, Monod H. Force-velocity relationship and maximal anaerobic power during cranking exercise in young swimmers. Int $J$ Sports Med. 1989; 10 (6): 439-45.

Whiting P. The 32nd America's Cup: A simple guide. Chichester, England: Wiley, 2007, pp. 72. 